Check for updates

\section{Oxford}

helen.salisbury@phc.ox.ac.uk Follow Helen on Twitter: @HelenRSalisbury Cite this as: BMJ 2021;373:n1256 http://dx.doi.org/10.1136/bmj.n1256 Published: 18 May 2021

\title{
PRIMARY COLOUR
}

\section{Helen Salisbury: GPs deserve better than this micromanagement}

\section{Helen Salisbury GP}

Last week I was working on a new timetable for our surgery, thinking about how and when we might switch back to letting patients book directly into face-to-face appointments. We'd like to be able to offer a choice of telephone, video, or in-person consultations, with the option of written questions too. Despite a recent NHS England document suggesting that GPs should aim to embed total triage we're concerned about its effect on our more vulnerable patients, so it didn't feature in our planning. This turned out to be just as well, as the next bit of guidance we received was a letter informing us of a new "standard operating procedure," whereby all patients requesting a face-to-face appointment should be offered one, with reception areas thrown open to all. ${ }^{1}$

These mixed and contradictory messages have angered GPs and drawn some sharp responses from the local medical committees that represent them. These include one from our regional committee reminding GPs that they're free to ignore any guidance that they believe is unhelpful to the safe and effective delivery of services. Other local responses have been less polite. ${ }^{2}$

GPs have worked their socks off during the pandemic. We've been adaptable and agile, coping with huge and rising demand while also administering $75 \%$ of the covid-19 vaccines. ${ }^{3}$ We've kept our eye on the ball and been ahead of the game throughout: we closed our doors to walk-ins before the first lockdown, switched to telephone-first for all appointments, and sourced our own personal protective equipment.

In my practice, we've constantly balanced the need to see patients face to face with the risk of having too many gathered in the waiting room. Covid is airborne and, even with two metres between chairs, we can't eliminate risk. Much as I'd love to return to seeing most of my patients in person, with the rise of the B.1.617.2 variant it would be foolhardy to return to pre-pandemic numbers at this time.

Interestingly, the guidance to throw wide our doors arrived on the same day as notice that we should accelerate our vaccine delivery because of the threat of this latest variant. What we need right now is for our NHS England colleagues to trust us to keep doing what we've been doing, providing the safest and most effective care we can in changing circumstances-which may vary depending on local prevalence-rather than issuing the frankly insulting attempts at micromanagement we're currently receiving.

There have been repeated calumnies about GPs in the popular press, including questions about when we're going to start work again. It's hard to avoid the conclusion that some of the "guidance" we're getting is politically motivated, continuing a false narrative of lazy doctors who need to be pushed into providing a proper service. We deserve better than this.

Competing interests: See www.bmj.com/about-bmj/freelance-contributors.

Provenance and peer review: Commissioned; not externally peer reviewed.

NHS England. Updated standard operating procedure (sop) to support restoration of general practice services. 13 May 2021. https://www.england.nhs.uk/coronavirus/wp-content/uploads/sites/52/2020/03/B0497GP-access-letter-May-2021-FINAL.pdf.

2 Philpotts E. GPs respond to "tone deaf" and "badly judged" NHSE face-to-face order. Pulse 2021 May 14. https://www.pulsetoday.co.uk/news/coronavirus/gps-respond-to-tone-deaf-and-badly-judgednhse-face-to-face-order/.

3 Bostock N. GP practices delivering $1 \mathrm{~m}$ appointments a week more than pre-pandemic, says NHS England. GP2021 Mar 25. https://www.gponline.com/gp-practices-delivering-1m-appointments-week-pre-pandemicsays-nhs-england/article/1711065. 